\title{
Fryns syndrome: Report of eight new cases
}

\section{To the Editor:}

Congenital diaphragmatic hernia $(\mathrm{CDH})$ and brachytelephalangy or nail hypoplasia are cardinal manifestation of Fryns syndrome (FS; OMIM 229850), ${ }^{1,2}$ but it is not uncommon that there are patients with FS without $\mathrm{CDH}$ or nail hypoplasia in whom the diagnosis is difficult to establish. In cases of presumed FS without $\mathrm{CDH}$ or brachytelephalangy, the presence of another affected sibling or clinical documentation of rare anomalies previously reported in patients with FS can be diagnostically useful. We report eight new cases of FS (Table 1) to document rare anomalies such as tracheoesophageal fistula, duodenal atresia, and intraabdominal organ fusion that may be diagnostically useful in FS patients without $\mathrm{CDH}$ or in whom the diagnosis is unclear.

The first child was a male born to a 33-year old mother at 23 weeks of gestation who died shortly after birth. Autopsy showed a left-sided, posterolateral CDH and pulmonary hypoplasia (total lung weight $2 \mathrm{~g}$ ). He had neck webbing, simple and low-set ears and retrognathia, hypoplasia of the distal fingers and toes, left talipes equinovarus and right talipes equinovalgus, mild right hydronephrosis with pelviureteric obstruction, and bilateral cryptorchidism (normal for gestation).

The second child was born to a 24-year old mother at 38 weeks of gestation. The baby had $\mathrm{CDH}$, hydronephrosis with anomalous implantation of the ureters, and Hirschsprung disease. Her medical history included severe esophageal reflux, recurrent respiratory tract infections, femoral osteomyelitis, possible seizure activity with an abnormal EEG, and an abnormal audiology exam by report. At 1 year of age, an upper respiratory tract infection resulted in respiratory depression and she died from an apneic episode. At autopsy, her weight was $7300 \mathrm{~g}(<5$ th percentile) and length was $68 \mathrm{~cm}(<5$ th percentile). Significant findings were an asymmetric depression of the right occipital bone, hypertelorism, an upturned, bifid nose, dysplastic ears, a midline cleft palate, short neck, mild pectus excavatum, and hypoplasia of all fingernails and toenails with short distal phalanges of the first fingers.

The third child was born to the same mother when she was 25 years old. In this pregnancy, a male baby was born at 36 weeks of gestation with $\mathrm{CDH}$ and died shortly after delivery. Postmortem examination confirmed left-sided $\mathrm{CDH}$ with bilateral pulmonary hypoplasia, a broad nasal bridge, dysplastic helices, micrognathia, and a cleft of the soft palate. The diagnosis of FS was made in this child despite the absence of phalangeal hypoplasia because of the previously affected sibling.

The fourth child was the first baby born to a 25 -year old mother. A female infant with $\mathrm{CDH}$ was delivered at 33 weeks of gestation and a decision was made to withdraw care because of poor respiratory status. Examination showed coarse facies with a broad forehead, infraorbital creases, a broad and flat nasal bridge, anteverted nares, low-set, dysplastic ears, and an everted lower lip. The neck was broad and her chest had small, wide-spaced nipples. There was brachydactyly, hypoplasia of distal phalanges of the digits, and nail hypoplasia with absence of the nails on the second and third toes. The umbilical cord had two vessels.

The fifth child was born to a 30-year old mother who had had a prior fetus affected with $\mathrm{CDH}$. This pregnancy was terminated at 22 weeks of gestation because of $\mathrm{CDH}$, imperforate anus, and tracheoesophageal fistula. Post mortem examination showed a male with small toenails and mild camptodactyly of the left toes. There was bilateral $\mathrm{CDH}$, with both lobes of the liver positioned in a V-shape around the heart, extreme pulmonary hypoplasia, and absent lung lobation, anal atresia, cryptorchidism (normal for gestation), and fusion of the abdominal organs with hepatic tissue extending from the liver to the right testis and to the left kidney, and the left adrenal gland was fused to the left lobe of the liver.

The sixth case was a female infant born at 38 weeks of gestation with a weight of $3050 \mathrm{~g}$ (50-75th percentile). She had left $\mathrm{CDH}$ and died on the first day of life. Autopsy showed hypoplasia of both lungs, right microphthalmia with corneal clouding, macrocephaly and frontal bossing, hypoplasia of the right face with a low-set right ear, and a flat nasal bridge. Internal examination revealed aplasia of the right olfactory bulb and tract, atrophy of the right optic nerve, mild coarctation of the aortic isthmus, a patent ductus arteriosus, and pancreatomegaly due to acinar and islet hyperplasia.

The last two cases were both born to the same parents. In the first pregnancy, premature rupture of the membranes occurred at 31 weeks of gestation and all growth parameters were consistent with 34 weeks of gestation. The infant died within the first hour of life. At autopsy, findings were right $\mathrm{CDH}$, severe pulmonary hypoplasia, atresia of the esophagus and proximal duodenum, renomegaly (combined weight $34.1 \mathrm{~g}$; average for gestation $=13.7 \mathrm{~g}$ ), a secundum atrial septal defect, a retroesophageal right subclavian artery, mild pancreatic islet cell hyperplasia, and a two-vessel umbilical cord. There was minor dysmorphism with posteriorly rotated ears and a small mouth. The second child born to the same parents was one of twins. She was born at 33 weeks of gestation with appropriate growth parameters, but was deceased at 24 hours of life. She had $\mathrm{CDH}$, hypoplasia of the left lung (weight $10 \mathrm{~g}$ at 33 weeks), a patent ductus arteriosus, and a Meckel diverticulum. The fingers were long and slender with normally formed nails.

Several of these patients have rare features previously reported in FS that provide a good illustration of the remarkable phenotypic variability of this condition, including duodenal atresia, esophageal atresia and tracheoesophageal fistula, ${ }^{2,3}$ and hypoplasia of the olfactory nerves. ${ }^{4,5}$ We were unable to find 
Table 1

Summary of physical findings in eight cases of Fryns syndrome

\begin{tabular}{|c|c|c|c|c|c|c|c|c|}
\hline Feature & 1 & 2 & 3 & 4 & 5 & 6 & 7 & 8 \\
\hline Family history of $\mathrm{CDH}$ & & + & + & & + & & + & + \\
\hline \multicolumn{9}{|l|}{ Diagnostic criteria } \\
\hline $\mathrm{CDH}$ & + & + & + & + & + & + & + & + \\
\hline Brachytelephalangy/nail hypoplasia & + & + & & + & + & & & \\
\hline Pulmonary hypoplasia & + & & + & + & + & + & + & + \\
\hline Dysmorphism & + & + & + & + & & + & + & \\
\hline Orofacial clefting & & + & + & & & & & \\
\hline Macrocephaly & & & & & & + & & \\
\hline Thick neck/nuchal skin & + & & & + & & & & \\
\hline Corneal clouding & & & & & & + & & \\
\hline Coarse facies & & + & & + & & & & \\
\hline Dysplastic low-set ears & + & + & + & & & + & + & \\
\hline Broad/flat nasal bridge & & + & + & + & & + & & \\
\hline Micro/retrognathia & + & & + & & & & & \\
\hline Cranial asymmetry & & + & & & & + & & \\
\hline Small olfactory bulb & & & & & & + & & \\
\hline Optic nerve atrophy & & & & & & + & & \\
\hline Atrial septal defect & & & & & & & + & \\
\hline Coarctation of aorta & & & & & & + & & \\
\hline $\mathrm{TOF}^{a} /$ bowel atresia & & & & & + & & + & \\
\hline Imperforate anus & & & & & + & & & \\
\hline Islet cell hyperplasia & & & & & & + & + & \\
\hline Hirschsprung disease & & + & & & & & & \\
\hline Renomegaly & & & & & & & + & \\
\hline Anomalous ureters & & + & & & & & & \\
\hline Hydronephrosis & + & + & & & & & & \\
\hline Organ fusion & & & & & + & & & \\
\hline Talipes & + & & & & & & & \\
\hline Two vessel cord & & & & + & & & + & \\
\hline Prenatal diagnosis & + & & + & + & + & & + & \\
\hline $\mathrm{AFP}^{b} /$ Triple screen & $+\mathrm{ve}$ & & & & & & & \\
\hline Karyotype & $46, X Y$ & 46, XX & & & & & $46, \mathrm{XY}$ & $46, \mathrm{XX}$ \\
\hline Gestational age & $23 \mathrm{w}$ & $38 \mathrm{w}$ & $36 \mathrm{w}$ & $33 \mathrm{w}$ & $22 \mathrm{w}$ & $38 \mathrm{w}$ & $31 \mathrm{w}$ & $33 \mathrm{w}$ \\
\hline Survival & $\mathrm{TAB}^{c}$ & $\begin{array}{c}\dagger 1 \\
\text { year }\end{array}$ & $\dagger$ day 1 & $\dagger$ & $\mathrm{TAB}^{c}$ & †day 1 & $\dagger$ day 1 & $\dagger$ day 1 \\
\hline
\end{tabular}

${ }^{a}$ tracheoesophageal atresia; ${ }^{b}$ alpha-feto protein; ${ }^{c}$ therapeutic abortion.

mention of the fusions between the liver, testis, kidney, and adrenal gland, but fusions of the adrenal gland to the liver, splenopancreatic fusion, and splenogonadal fusion have each been described once in FS. ${ }^{6}$ These features may be useful diagnostic markers of FS in patients without $\mathrm{CDH}$ or for patients with $\mathrm{CDH}$ without nail hypoplasia.
Hirschsprung disease is a rare but notable malformation in FS with four previously reported cases. ${ }^{7}$ Hirschsprung disease results from aberrant migration of neural crest cells and this case supports the hypothesis that aberrant neural crest cell migration may be pathogenically important in at least some cases with FS. ${ }^{8}$ Further support for the importance of aberrant neural crest cell mi- 
gration comes from cardiac malformations consistent with abnormal cardiac neural crest cell migration in FS, such as Tetralogy of Fallot and interrupted aortic arch. ${ }^{2}$ In addition, dysregulated cell migration may be important in the pathogenesis of isolated diaphragmatic hernia. Mice with haploinsufficiency for the slit3 gene lack the corresponding protein that acts as a guidance cue for the migration of axons and myoblasts. These knockout mice have had herniation of the septum transversum of the diaphragm. ${ }^{8}$

We welcome further discussion and case submission to continue the study of this phenotypically complex and heterogeneous syndrome.

\section{ACKNOWLEDGMENT}

This work was supported by REAC grant number 36248524269, University of California, San Francisco. These studies were performed in part in the Pediatric Clinical Research Center, Moffitt Hospital, University of California, San Francisco, with funds provided by the National Center for Research Resources, 5 M01 RR-01271, U.S. Public Health Service.

Anne M. Slavotinek, MB, BS, PhD Department of Pediatrics Division of Clinical Genetics University of California San Francisco, California

Galen Schauer, MD Department of Pathology Children's Hospital and Clinics Minneapolis, Minnesota

Goeff Machin, MD

Kaiser Permanente Medical Center Oakland, California
Majed Dasouki, MD Section of Medical Genetics and Molecular Medicine

Children's Mercy Hospital

Kansas City, Missouri

Maria E. Rueda-Pedraza, MD Frank Chiricosta, MD

Department of Pathology

Walter Reed Army Medical Center Washington, DC

Roberta Keller, MD

Department of Pediatrics

Division of Neonatology

University of California

San Francisco, California

\section{References}

1. Fryns JP, Moerman F, Goddeeris P, Bossuyt C, Van den Berghe H. A new lethal syndrome with cloudy corneae, diaphragmatic defects and distal limb deformities. Hum Genet 1979;50:65-70.

2. Slavotinek AM. Fryns syndrome: a review of the phenotype and diagnostic guidelines. Am J Med Genet 2004;124A:427-433.

3. Ayme S, Julian C, Gambarelli D, Mariotti B, Luciani A, Sudan N, Maurin N, Philip N, Serville F, Carles D, et al. Fryns syndrome: report on 8 new cases. Clin Genet 1989;35: 191-201.

4. Fitch N, Srolovitz H, Robitaille Y, Guttman F. Absent left hemidiaphragm, arhinen cephaly, and cardiac malformations. J Med Genet 1978;15:399-401.

5. Cunniff C, Jones KL, Saal HM, Stern HJ. Fryns syndrome: an autosomal recessive disorder associated with craniofacial anomalies, diaphragmatic hernia, and distal digital hypoplasia. Pediatrics 1990;85:499-504.

6. Van Wymersch D, Favre R, Gasser B. Use of three-dimensional ultrasound to establish the prenatal diagnosis of Fryns syndrome. Fetal Diagn Ther 1996;11: 335-340.

7. Ramsing M, Gillessen-Kaesbach G, Holzgreve W, Fritz B, Rehder H. Variability in the phenotypic expression of Fryns syndrome: A report of two sibships. Am J Med Genet 2000;95:415-424.

8. Yuan W, Rao Y, Babiuk RP, Greer JJ, Wu JY, Ornitz DM. A genetic model for a central (septum transversum) congenital diaphragmatic hernia in mice lacking Slit3. Proc Natl Acad Sci U S A 2003;100:5217-5222. 